\title{
Direct and indirect costs of adult patients with chronic rhinosinusitis with nasal polyps*
}

\section{E.S. Lourijsen, W.J. Fokkens, S. Reitsma}

Department of otorhinolaryngology, Amsterdam UMC, location AMC, the Netherlands
Rhinology 58: 3, 213 - 217, 2020

https://doi.org/10.4193/Rhin19.468

*Received for publication:

December 27, 2019

Accepted: January 13, 2020

\begin{abstract}
Background: European direct and indirect cost data is missing for patients with chronic rhinosinusitis with nasal polyps (CRSwNP). This study was aimed to establish the economic burden of CRSwNP based on a Dutch cohort of patients.
\end{abstract}

Methods: A cross-sectional study was performed in adult patients with CRSwNP ( $N=115)$ to calculate mean annual direct medical costs and indirect costs per patient with CRSwNP. Outpatient visits, general practitioner visits, first aid visits, hospitalisation and patient travel expenses were measured with the iMTA medical consumption questionnaire. Missed workdays (absenteeism) and decreased productivity during paid work (presenteeism) or during daily life were measured with the and the iMTA productivity cost questionnaire.

Results: Total direct costs were $€ 1501$ per patient/year, primarily due to outpatient department visits and hospitalisation. Indirect costs were $€ 5659$ per patient/year, with productivity losses as major cost expense.

Conclusion: Adult patients with CRSwNP have higher indirect costs than direct costs and this forms a substantial burden to society. Total annual costs of patients with CRSwNP are estimated to be 1,9 billion/year in the Netherlands.

Key words: chronic rhinosinusitis with nasal polyps, cost of illness, economic burden of disease, health care costs, health surveys

\section{Introduction}

Chronic rhinosinusitis (CRS) is an inflammatory disease of the nose and the paranasal sinuses characterized by nasal blockage or nasal discharge with or without facial pressure/pain or reduction of smell ${ }^{(1)}$. CRS is a highly common disease in Europe affecting about $11 \%$ of people based on epidemiologic data only ${ }^{(1,2)}$. However, when combining epidemiologic CRS with clinically based CRS (depending on a CT-scan Lund-Mackay cut-off point) the 'real life' prevalence in the general population is lower, between $3.0-6.4 \%{ }^{(3)}$. Treatment consists of local or systemic therapy and endoscopic sinus surgery in case where medical treatment has failed. A substantial impact on most aspects of quality of life is well-recognised as well as a decrease in work productivity $^{(1,4-8)}$. The relatively high prevalence and the chronicity of the disease lead to high costs, due to healthcare resource use (direct costs) and due to less productivity at work (presenteeism) or absenteeism (indirect costs) ${ }^{(1,2,9)}$. Evidence shows that the main costs are attributable to these indirect costs ${ }^{(10)}$. Indirect costs are very important to understand from a socioeconomic point of view, since most patients with CRS are of working age (between 30-50 years of age ${ }^{(1)}$. Recent data suggests that costs of CRS are increasing in the US; the latest report in 2017 estimated indirect costs to be about $\$ 20$ billion for CRS in general ${ }^{(11)}$. However, also the total direct costs of CRS in the US are increasing and are estimated to be between $\$ 10$ and $\$ 13$ billion annually ${ }^{(11)}$. CRS with nasal polyps (CRSwNP) has a significant incremental increase in direct costs on a yearly basis compared to without nasal polyps (CRSsNP) or no diagnosis of CRS ${ }^{(12,13)}$. In Europe, there are hardly any data on costs of CRS. We are aware of two studies evaluating direct costs of CRSsNP ${ }^{(4,14)}$. We are not aware of any European data on indirect cost of CRSwNP. To define the importance of CRSWNP as a burdensome diagnosis, the relative 
economic impact of CRSwNP to a population needs to be clear including indirect costs. This study was aimed to establish the total economic burden of CRSwNP based on a Dutch cohort of patients.

\section{Material and methods}

Study design and sample population

A cross-sectional study was designed with inclusion of adult patients with CRSwNP from three academic hospitals and 11 local hospitals in the Netherlands. Inclusion criteria were patients older than 17 years of age with diagnosed CRSwNP. Exclusion criteria were comorbid vasculitis, cystic fibrosis, sarcoidosis, sinonasal malignancy or known immunodeficiency. Data on age, gender, smoking status, diagnosed asthma or diagnosed NSAIDexacerbated respiratory disease (N-ERD) ${ }^{(15)}$ and any previous sinus surgery were recorded. Ethical approval was obtained from the Medical Ethics Committee located in the Amsterdam UMC, location Academic Medical Centre (Amsterdam, The Netherlands). All patients signed written informed consent.

\section{Outcome measures}

Outcome parameters were direct and indirect costs. Direct costs of interest were outpatient visits, general practitioner visits, first aid visits, hospitalisation, endoscopic sinus surgery, use of at least one course of antibiotics or systemic corticosteroids in the previous year (specifically for CRSwNP) and patient travel expenses. Indirect costs were composed of missed workdays (absenteeism) and decreased productivity during paid work (presenteeism) or during daily life (unpaid work). Two patient-reported outcome measurements were used to measure the direct and indirect costs: the medical consumption questionnaire (iMCQ) and the productivity cost questionnaire (iPCQ). The Institute for Medical Technology Assessment (iMTA), an independent scientific committee that performs health economic research in the Netherlands, developed these questionnaires. Patients were able to complete the questionnaires online with a personal token ${ }^{(16,17)}$. The iMCQ questions about individual healthcare resource use over the past three months and the iPCQ about any productivity losses in the past 4 weeks. Local nasal steroid sprays or drops were not included in the current evaluation, since this parameter was not included in the $\mathrm{MCQ}$. Total yearly estimates were calculated after extrapolation of the iMCQ (3 months) and iPCQ (1 month) to 12 months. Yearly data on endoscopic sinus surgery, antibiotic and systemic corticosteroid use were retrieved from the electronic patient medical record.

\section{Cost calculations}

The friction cost method was used for presenteeism and absenteeism, in accordance with the current guidelines on performing health economic evaluations, which prefers the friction cost method above the human capital approach ${ }^{(18)}$. All costs are
Table 1. Baseline characteristics of CRSwNP study population $(\mathrm{N}=115)$.

\begin{tabular}{|lcc|}
\hline Baseline characteristic & N & $\%$ \\
\hline Male & 65 & 56.5 \\
\hline Female & 50 & 43.5 \\
\hline Payed worker & 83 & 72 \\
\hline Current smoker & 16 & 13.9 \\
\hline Former smoker & 51 & 44.3 \\
\hline Asthma & 68 & 59.1 \\
\hline N-ERD & 24 & 20.9 \\
\hline Previous sinus surgery & 79 & 68.7 \\
\hline
\end{tabular}

$\mathrm{N}-\mathrm{ERD}=\mathrm{NSAID}$-exacerbated respiratory disease.

expressed in euros $(€)$ and are based on 2014 reference prices if available ${ }^{(18)}$. Prices of endoscopic sinus surgery for CRS were derived from the Dutch website of the 'NederlandseZorgautoriteit' (2018 data, www.opendisdata.nl/msz/zorgproduct/109799004). Medication costs were calculated using the Dutch website https://www.medicijnkosten.nl ${ }^{(18)}$. Costs due to prescriptions of short courses of systemic corticosteroids were calculated by applying 'Prednison' 30 mg for 10 days as standard course and costs due to prescriptions of antibiotics by applying 'Augmentin' $500 / 125 \mathrm{mg}$ for 7 days. Both chosen prescriptions are frequently used in the Netherlands for an exacerbation of CRSwNP.

\section{Statistical analysis}

Descriptive analyses were conducted and frequencies or means with SD were reported for direct and indirect outcome measures. Statistical analyses were performed using IBM SPSS Statistics, version 25.0.

\section{Results}

In total 115 patients (56.5\% males and $43.5 \%$ females) with CRSwNP were enrolled with a mean age of 50.8 (SD 12.7) years. The characteristics are outlined in Table 1 . In total $44.3 \%$ of patients were former smokers, $59.1 \%$ had comorbid asthma and $20.9 \%$ had NSAID-exacerbated respiratory disease (N-ERD). Previous endoscopic sinus surgery was performed in $68.7 \%$ of patients.

\section{Direct costs}

Annual direct costs were $€ 1501,20$ per individual patient with CRSwNP. The largest contributors to these costs were outpatient department visits, endoscopic sinus surgery and hospitalisation. An overview of expenditures is presented in Table 2. Patient travel expenses to hospitals covered a mean $€ 33.80$ (SD 109,4) yearly per patient. Additional yearly parking costs were $€ 14.53$ per patient (SD 84,5). 
Table 2. Average annual direct expenditures with accompanying total direct costs per individual with CRSwNP in $€(N=115)$.

\begin{tabular}{|lcc|}
\hline Expenditure & Mean (SD) & Direct costs (€) \\
\hline ENT outpatient department visits & $4.59(1.8)$ & $417.81(161.7)$ \\
\hline Total outpatient department visits & $7.89(7.0)$ & $718.50(636.8)$ \\
\hline General practitioner visits & $3.48(4.4)$ & $114.78(146.8)$ \\
\hline First aid visits & $0.24(0.9)$ & $63.06(248.8)$ \\
\hline Days of hospitalisation & $0.66(3.7)$ & $314.57(1726.7)$ \\
\hline No. of endoscopic sinus surgeries & $0.087(0.3)$ & $240.43(782.5)$ \\
\hline Course of antibiotics & $0.31(0.4)$ & $0.95(1.1)$ \\
\hline $\begin{array}{l}\text { Short course of systemic cortico- } \\
\text { steroids for CRSwNP }\end{array}$ & $0.42(0.5)$ & $0.64(0.96)$ \\
\hline
\end{tabular}

ENT $=$ Ear-, Nose- Throat; CRSwNP $=$ Chronic Rhinosinusitis with Nasal Polyps

\section{Indirect costs}

Total indirect costs were at least $€ 5659,28$ per patient/year due to productivity losses and absenteeism. In Table 3 annual indirect costs and total days of absence and productivity losses are shown for patients with paid work and without paid work. Patients were absent from work for a mean 10,55 (SD 44,4) days/ year). Short-term absence (less than four consecutive weeks) costed a mean $€ 644,41$ (SD 2777,8) per patient/year ( $N=115)$. In addition, some patients also experienced long-term absence from work (longer than four consecutive weeks). Long-term absence costed an additional $€ 796,77(5617,0)$ yearly per patient $(\mathrm{N}=115)$. A reduction in effectiveness of work was experienced by $34,9 \%$ of patients with a mean overall productivity of 7,48 (SD 2.09, Likert scale 0-10, in which 10 indicates normal productivity). Presenteeism costs were $€ 1447,28(5078,1)$ per patient/ year $(\mathrm{N}=115)$.

\section{Total costs}

Direct and indirect costs are $€ 7160,54$ yearly per patient. The division of costs is illustrated in Figure 1. We used the $\sim 2 \%$ prevalence of CRSwNP and the current Dutch adult population of 13,4 million people to calculate estimates of total annual costs; direct costs would be $€ 402$ million/year and indirect costs would be at least $€ 1.5$ billion/year.

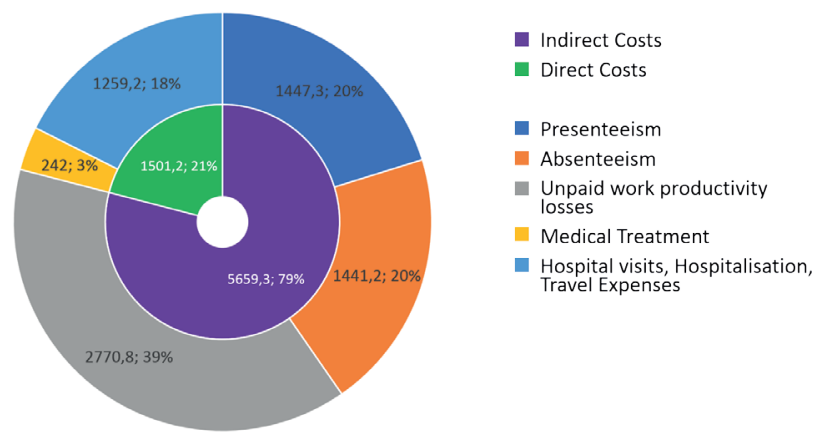

Figure 1. Division of total annual costs per patient into subcategories. Mean $€$ and percentage of total costs are presented. Total costs per patient: $€ 7160$.

\section{Discussion}

This evaluation of the economic burden of CRSwNP found a large cost difference between direct medical costs and indirect costs. Mean direct medical costs were at least $€ 1501$ and mean indirect costs were at least $€ 5659$ annually per patient. Larger indirect costs were expected based on the figures from the Unites States ${ }^{(11)}$.

Annual direct and indirect costs of CRS on an individual patient level have been evaluated before ${ }^{(4,12,13,19-22)}$, however there are no studies that evaluated CRSsNP and CRSwNP as separate disease phenotypes for indirect costs. Moreover, not many European cost evaluations are available to compare with ${ }^{(4,14)}$. Bhattacharyya demonstrated in 20039 that patients with CRS $(\mathrm{N}=322)$ in the United States were absent for 4,8 days annually (23). A follow-up study in 2009 using data from the National Health Interview Survey reported that patients with any form of sinusitis missed 5.7 days annually ${ }^{(21)}$. CRSsNP patients in the United States were absent for 5,8 days annually (21). Our absence rate of 10,6 days for CRSwNP is significantly higher. Rudmik et al. showed that patients with recalcitrant $\mathrm{CRS}(\mathrm{N}=55)$ had mean annual presenteeism and absenteeism rates of 25-39 days/year, with costs $\$ 10,000$ per patient / year ( €9000). Apart from severity, the type of CRS symptoms is also of influence on indirect costs ${ }^{(24)}$. The current study did not evaluate the influence of severity and symptoms on costs in patients with CRSwNP. The Dutch Central Bureau of Statistics published data of absenteeism rates in the general population (2018). Compared to

Table 3. Average annual days of absence and productivity losses with accompanying total indirect costs in Euros per patient with CRSwNP.

\begin{tabular}{|c|c|c|c|c|c|c|}
\hline Expenditure & $\begin{array}{l}\text { Paid work } \\
\text { (N=83) }\end{array}$ & Costs in $€$ & $\begin{array}{c}\text { No paid } \\
\text { work }(\mathrm{N}=32)\end{array}$ & Costs in $€$ & $\begin{array}{c}\text { Total } \\
(\mathrm{N}=115)\end{array}$ & Costs in $€$ \\
\hline Absence (days, SD) & $10.55(44.4)$ & $1996.82(7212.9)$ & NA & NA & NA & $1441.18(6183.1)$ \\
\hline Work-related lost productivity (days, SD) & $30.36(65.9)$ & $2005.27(5892.2)$ & NA & NA & NA & $1447.28(5078.1)$ \\
\hline Unpaid work lost productivity (days, SD) & $15.90(66.0)$ & $1877.77(11555.0)$ & $43.88(98.7)$ & $5087.18(21718.7)$ & $23.69(77.1)$ & $2770.83(15046.4)$ \\
\hline Total no. of days (SD) & $56.82(124.9)$ & $5879.85(18155.2)$ & $43.88(98.7)$ & $5078.18(21718.7)$ & $23.69(77.1)$ & $5659.28(19117.6)$ \\
\hline
\end{tabular}


their reported average 7,6 days absence/year, our finding of 10,6 days/year is significantly higher than what would be expected as normal. When these additional $\sim 3$ workdays would be multiplied with $2 \%$ (prevalence of CRS 1-4\%) of 13,4 million adults, this would generate 1 million lost workdays/year ${ }^{(25)}$. Some caution is warranted with this estimate given this is a cross-sectional study. However, our findings generally support the available evidence that absenteeism forms a large expenditure.

The main costs of patients with CRSwNP were due to productivity losses in both paid and unpaid patients. Since $72 \%$ of patients had paid work, we felt that we could divide total costs among all included patients to provide an estimate of mean annual indirect costs per patient independent of working status. Higher productivity losses in unpaid patients during unpaid work were found. An explanation could be older age ( $50 \%$ of patients were retired, $\mathrm{N}=16$ ).

Direct costs formed only $21 \%$ of total costs and main contributors were outpatient department visits and hospitalisation. Murphy et al. ${ }^{(19)}$ showed higher direct costs ( €2400) of CRS patients in the United States compared to controls, mainly due to non-urgent outpatient visits ( €920) and drug treatment ( $€ 320)$. A good comparison could not be made since our study did not include full pharmacy costs. Van Agthoven calculated direct costs of severe CRS patients to be $€ 1792 /$ year $(N=35)^{(4)}$. This study also included costs of medical treatment, but seems to compare well to our current direct cost value of $€ 1501$. The cost estimates of this study are reflections of CRSwNP burden in the Netherlands measured by the IMCQ and PCQ. Although the prevalence of CRSwNP can be similar between countries, costs do not necessarily have to be so. A generalisation cannot be made directly due to country-level differences in medical costs, reference prices used and mean income per individual.

This study has some limitations: 1 . This was a cross-sectional study design with extrapolation of data. Care must be taken with cost estimates, since the moment of assessment of questionnaires is not guaranteed to be representative. We feel that the sample size is large enough to provide reliable cost figures; 2. Self-reported data in questionnaires are subject to recall bias and so the results must be interpreted with caution; however, these questionnaires are validated to such an extent that recall bias is limited; 3. Intranasal (mainstay) therapy for CRSwNP was not included in our analysis and consequently annual direct costs will most likely be an underestimation of total costs.
The focus of this study was to evaluate direct and indirect costs per patient with CRSwNP in general, rather than to make a comparison with objective findings of disease or severity of disease based on validated patient reported outcome measurements for CRSwNP, such as the SNOT-22 ${ }^{(26)}$. It would be very helpful in future studies to relate healthcare utilization costs and costs of lost productivity or absenteeism to the severity of sinonasal symptoms measured by the SNOT-22, total symptom scores or a more objective measurement such as nasal endoscopy.

Our findings show a skewed distribution of costs in Dutch patients with CRSwNP indicating that indirect costs, particularly productivity losses, form the main part of the large annual costs found. Future interventions should be directed to lowering absence rates and improve productivity at work and at home. More (European) research should be performed on the extent of productivity losses in patient with CRSwNP and the influence of treatment on productivity.

\section{Conclusion}

We showed the economic burden of CRSwNP to be at least $€ 1501$ per patient/year for direct medical costs and $€ 5659$ per patient/year due to productivity losses and absenteeism. The high indirect costs produce a significant burden to the Dutch economy, to companies and to patients. In current times, healthcare policy makers become more interested in costs of illness and the effect of the applied interventions on these costs, which further justify any procedure or medical intervention for CRSwNP. Therefore, awareness must be created among ENTspecialists that indirect costs form the biggest cost expense.

\section{Abbreviations}

CRS: Chronic Rhinosinusitis with nasal polyps; CRSwNP Chronic Rhinosinusitis with nasal polyps; iMCQ: iMTA medical consumption questionnaire; iPCQ: iMTA productivity cost questionnaire; N-ERD: NSAID-exacerbated respiratory disease.

\section{Authorship contribution}

As per ICMJE recommendations: 1) Contributions to conception and design of, or acquisition of data and analysis and interpretation of data; 2) drafting the article of revising it critically for important intellectual content; 3) final approval of the version to be published: EL 1,2,3; WJF: 1,2,3; SR 2,3

\section{Conflict of interest}

None

\section{References}

1. Fokkens WJ, Lund VJ, Mullol J, Bachert C Alobid I, Baroody F, et al. European Position Paper on Rhinosinusitis and Nasal Polyps 2012. Rhinology Supplement. 2012;23:pre- ceding table of contents, 1-298.

2. Hastan D, Fokkens WJ, Bachert C, Newson RB, Bislimovska J, Bockelbrink A, et al. Chronic rhinosinusitis in Europe--an underestimated disease. A GA(2)LEN study.
Allergy. 2011;66(9):1216-23.

3. Dietz de Loos D, Lourijsen ES, Wildeman MAM, Freling NJM, Wolvers MDJ, Reitsma $S$, et al. Prevalence of chronic rhinosinusitis in the general population based on sinus 
radiology and symptomatology. J Allergy Clin Immunol. 2019;143(3):1207-14.

4. van Agthoven M, Uyl-de Groot CA, Fokkens WJ, van de Merwe JP, Busschbach JJ. Cost analysis of regular and filgrastim treatment in patients with refractory chronic rhinosinusitis. Rhinology. 2002;40(2):69-74.

5. DeConde AS, Soler ZM. Chronic rhinosinusitis: Epidemiology and burden of disease. Am J Rhinol Allergy. 2016;30(2):134-9.

6. Smith KA, Rudmik L. Medical therapy, refractory chronic rhinosinusitis, and productivity costs. Curr Opin Allergy Clin Immunol. 2017;17(1):5-11.

7. Rudmik L, Smith TL. Quality of life in patients with chronic rhinosinusitis. Curr Allergy Asthma Rep. 2011;1 1(3):247-52.

8. Soler ZM, Mace J, Smith TL. Symptombased presentation of chronic rhinosinusitis and symptom-specific outcomes after endoscopic sinus surgery. Am J Rhinol 2008;22(3):297-301.

9. Caulley L, Thavorn K, Rudmik L, Cameron C, Kilty SJ. Direct costs of adult chronic rhinosinusitis by using 4 methods of estimation: Results of the US Medical Expenditure Panel Survey. J Allergy Clin Immunol. 2015;136(6):1517-22.

10. Blackwell DL, Collins JG, Coles R. Summary health statistics for U.S. adults: National Health Interview Survey, 1997. Vital and health statistics Series 10, Data from the National Health Survey. 2002(205):1-109.

11. Rudmik L. Economics of Chronic Rhinosinusitis. Curr Allergy Asthma Rep. 2017;17(4):20

12. Bhattacharyya N. Incremental health care utilization and expenditures for chronic rhinosinusitis in the United States. Ann Otol Rhinol Laryngol. 2011;120(7):423-7.
13. Bhattacharyya $N$, Villeneuve $S$, Joish VN, Amand C, Mannent L, Amin N, et al. Cost burden and resource utilization in patients with chronic rhinosinusitis and nasal polyps. Laryngoscope. 2019;129(9):1969-75.

14. Berggren F, Johansson L. Cost effectiveness of nasal budesonide versus surgical treatment for nasal polyps. PharmacoEconomics. 2003;21(5):351-6.

15. Kowalski ML, Agache I, Bavbek S, Bakirtas A, Blanca M, Bochenek G, et al. Diagnosis and management of NSAID-Exacerbated Respiratory Disease (N-ERD)-a EAACI position paper. Allergy. 2019;74(1):28-39.

16. Bouwmans C H-vRL, Koopmanschap M, Krol M, Severens H, Brouwer W. Handleiding iMTA Productivity Cost Questionnaire (iPCQ). Rotterdam: iMTA, Erasmus Universiteit. 2013.

17. Bouwmans C H-vRL, Koopmanschap M, Krol M, Severens J, Brouwer W. Handleiding iMTA Medical Cost Questionnaire (iMCQ). Rotterdam: iMTA, Erasmus Universiteit Rotterdam. 2013.

18. Hakkaart-van Roijen L vdLN, Bouwmans C, Kanters T, Tan S. Methodologie van kostenonderzoek en referentieprijzen voor economische evaluaties in de gezondheidszorg. In opdracht van College van Zorgverzekeringen. 2015.

19. Murphy MP, Fishman P, Short SO, Sullivan SD, Yueh B, Weymuller EA, Jr. Health care utilization and cost among adults with chronic rhinosinusitis enrolled in a health maintenance organization. Otolaryngol Head Neck Surg. 2002;127(5):367-76.

20. Bhattacharyya N. Assessing the additional disease burden of polyps in chronic rhinosinusitis. Ann Otol Rhinol Laryngol. 2009;118(3):185-9.
21. Bhattacharyya N. Contemporary assessment of the disease burden of sinusitis. Am J Rhinol Allergy. 2009;23(4):392-5.

22. Yip J, Vescan AD, Witterick IJ, Monteiro E. The personal financial burden of chronic rhinosinusitis: A Canadian perspective. Am J Rhinol Allergy2017;31(4):216-21.

23. Bhattacharyya N. The economic burden and symptom manifestations of chronic rhinosinusitis. Am J Rhinol Allergy 2003;17(1):2732.

24. Campbell AP, Phillips KM, Hoehle LP, Feng AL, Bergmark RW, Caradonna DS, et al. Depression symptoms and lost productivity in chronic rhinosinusitis. Ann Allergy Asthma Immunol. 2017;1 18(3):286-9.

25. CBS. Bevolkingkern cijfers. https://opendatacbsnl/statline/\#/CBS/nl/dataset/37296ned/ table?ts=1576979260260. 2019.

26. Hopkins C, Gillett S, Slack R, Lund VJ, Browne JP. Psychometric validity of the 22-item Sinonasal Outcome Test. Clin Otolaryngol. 2009;34(5):447-54.

Prof. dr. W.J. Fokkens

Amsterdam UMC, location AMC

Meibergdreef 9

1105 AZ Amsterdam

The Netherlands

Tel: +31 205663889

E-mail:

w.j.fokkens@amsterdamumc.nl 